NASA/TM-2010-216768

\title{
Effect of Turbulence Modeling on an Excited Jet
}

\section{Clifford A. Brown}

Glenn Research Center, Cleveland, Ohio

Ray Hixon

University of Toledo, Toledo, Ohio 


\section{NASA STI Program . . . in Profile}

Since its founding, NASA has been dedicated to the advancement of aeronautics and space science. The NASA Scientific and Technical Information (STI) program plays a key part in helping NASA maintain this important role.

The NASA STI Program operates under the auspices of the Agency Chief Information Officer. It collects, organizes, provides for archiving, and disseminates NASA's STI. The NASA STI program provides access to the NASA Aeronautics and Space Database and its public interface, the NASA Technical Reports Server, thus providing one of the largest collections of aeronautical and space science STI in the world. Results are published in both non-NASA channels and by NASA in the NASA STI Report Series, which includes the following report types:

- TECHNICAL PUBLICATION. Reports of completed research or a major significant phase of research that present the results of NASA programs and include extensive data or theoretical analysis. Includes compilations of significant scientific and technical data and information deemed to be of continuing reference value. NASA counterpart of peer-reviewed formal professional papers but has less stringent limitations on manuscript length and extent of graphic presentations.

- TECHNICAL MEMORANDUM. Scientific and technical findings that are preliminary or of specialized interest, e.g., quick release reports, working papers, and bibliographies that contain minimal annotation. Does not contain extensive analysis.

- CONTRACTOR REPORT. Scientific and technical findings by NASA-sponsored contractors and grantees.
- CONFERENCE PUBLICATION. Collected papers from scientific and technical conferences, symposia, seminars, or other meetings sponsored or cosponsored by NASA.

- SPECIAL PUBLICATION. Scientific, technical, or historical information from NASA programs, projects, and missions, often concerned with subjects having substantial public interest.

- TECHNICAL TRANSLATION. Englishlanguage translations of foreign scientific and technical material pertinent to NASA's mission.

Specialized services also include creating custom thesauri, building customized databases, organizing and publishing research results.

For more information about the NASA STI program, see the following:

- Access the NASA STI program home page at http://www.sti.nasa.gov

- E-mail your question via the Internet to help@ sti.nasa.gov

- Fax your question to the NASA STI Help Desk at $443-757-5803$

- Telephone the NASA STI Help Desk at 443-757-5802

- Write to: NASA Center for AeroSpace Information (CASI) 7115 Standard Drive Hanover, MD 21076-1320 
NASA/TM-2010-216768

AIAA-2009-3191

\section{Effect of Turbulence Modeling on an Excited Jet}

\section{Clifford A. Brown}

Glenn Research Center, Cleveland, Ohio

Ray Hixon

University of Toledo, Toledo, Ohio

Prepared for the

15th Aeroacoustics Conference (30th AIAA Aeroacoustics Conference)

cosponsored by AIAA and CEAS

Miami, Florida, May 11-13, 2009

National Aeronautics and

Space Administration

Glenn Research Center

Cleveland, Ohio 44135 
This work was sponsored by the Fundamental Aeronautics Program at the NASA Glenn Research Center.

Level of Review: This material has been technically reviewed by technical management.

Available from

NASA Center for Aerospace Information

7115 Standard Drive

Hanover, MD 21076-1320
National Technical Information Service 5301 Shawnee Road Alexandria, VA 22312

Available electronically at http://gltrs.grc.nasa.gov 


\title{
Effect of Turbulence Modeling on an Excited Jet
}

\author{
Clifford A. Brown \\ National Aeronautics and Space Administration \\ Glenn Research Center \\ Cleveland, Ohio 44135 \\ Ray Hixon \\ University of Toledo \\ Toledo, Ohio 43606
}

\begin{abstract}
The flow dynamics in a high-speed jet are dominated by unsteady turbulent flow structures in the plume. Jet excitation seeks to control these flow structures through the natural instabilities present in the initial shear layer of the jet. Understanding and optimizing the excitation input, for jet noise reduction or plume mixing enhancement, requires many trials that may be done experimentally or computationally at a significant cost savings. Numerical simulations, which model various parts of the unsteady dynamics to reduce the computational expense of the simulation, must adequately capture the unsteady flow dynamics in the excited jet for the results are to be used. Four CFD methods are considered for use in an excited jet problem, including two turbulence models with an Unsteady Reynolds Averaged Navier-Stokes (URANS) solver, one Large Eddy Simulation (LES) solver, and one URANS/LES hybrid method. Each method is used to simulate a simplified excited jet and the results are evaluated based on the flow data, computation time, and numerical stability. The knowledge gained about the effect of turbulence modeling and CFD methods from these basic simulations will guide and assist future three-dimensional (3-D) simulations that will be used to understand and optimize a realistic excited jet for a particular application.
\end{abstract}

\section{Introduction}

The flow dynamics in a high-speed jet are dominated by the unsteady turbulent flow structures that characterize the energy cascade in the jet plume. These flow structures, which range in size from largescale eddies on the order of the jet diameter that transport energy to the extremely small-scale eddies that dissipate energy through viscous forces, originate in the naturally unstable free-shear boundary layer formed between the high-speed jet flow and the surrounding fluid. As the fluids mix in the jet plume, Kelvin-Helmholtz instability waves are formed. These instability waves grow and decay as the jet develops, governing the formation and destruction of the unsteady turbulent flow structures. Jet excitation must exploit these natural instabilities to exert control on the turbulent structures or the energy of the jet will overwhelm the input perturbation. If perturbations are input at the nozzle exit impact the jet where the flow structures are smaller and less energetic, then large changes to the to the jet flow downstream can be created with a relatively small energy input. Moreover, the downstream characteristics of the jet plume can be predetermined by selecting an appropriate instability wave (mode and frequency) to amplify with the input perturbation.

Jet excitation has many potential uses. It may be used to reduce the thermal signature of the jet or to mitigate the noise generated. Proper excitation, however, requires intelligently selecting the best excitation input from the infinite number of possibilities to optimize the effect. Modern experimental techniques, such as particle image velocimetry and phased array microphones, can provide detailed flow and acoustic information that could be used to optimize the excitation but these experiments are too costly for the large number of cases required for a true optimization, especially at the larger and more realistic facilities. Numerical simulations can provide a cost effective alternative to experiments for optimizing the excitation input, leaving only the best cases to be confirmed using experiments. 
Direct Numerical Simulations (DNS) solve the compressible Navier-Stokes equations to calculate the complete history of a flow without modeling assumptions. In a DNS calculation, all time- and lengthscales are resolved throughout the flow, necessitating very small time steps and very fine grid spacing. This limits the use of DNS for a realistic high Reynolds number jet flow because resolving the wide range of time- and length-scales between the nozzle boundary layer and the turbulent eddies in the plume quickly becomes computationally overwhelming. Thus, part or all of the unsteady turbulent flow cannot be directly simulated and the unresolved flow must be modeled. As more of the flow is modeled rather than resolved, the computational effort is reduced but at a cost; the solution becomes more dependent of the modeling assumptions. It is necessary, therefore, to understand the methods and assumptions used in the simulations in order to balance quality of the result with the computational expense required.

A jet excitation test case has been developed to study the advantages and disadvantages of four common turbulent flow simulation models. The simulation results for these test cases are not intended to exactly recreate experimental results but rather to provide a basis, at minimal computational expense, from which to choose the best method for future simulations and to intelligently begin these future simulations with some knowledge of the grid and time resolution required to achieve more accurate results. Although the NASA Fundamental Aeronautics Program, under the Supersonics project, is supporting this research with the goal of developing the next generation of technology to reduce the environmental impact of noise around airports with minimal impact of engine performance, the knowledge gained from these simulations can be applied to any application of jet excitation.

\section{The Problem-Jet Excitation}

Jet excitation amplifies instabilities naturally present in a jet to alter the downstream development of the jet. Actuators are used, typically at or near the nozzle exit to excite these instabilities. Historically, many different actuators have been used to in excitation experiments, including loudspeakers, air injection, and synthetic jets. More recently, the Localized Arc Filament Plasma Actuators (LAFPA) have shown considerable promise as high amplitude, high frequency flow actuators (Refs. 1 and 2). Developed at Ohio State University, the LAFPA use a high temperature spark to generate a shock wave that impacts the jet flow at the nozzle exit. These actuators are a good test of the CFD methods for a couple of reasons. First, the on or off nature of the LAFPA spark challenge the numerical stability of the CFD method. Second, the sharp gradients generated offer a real test of the codes ability to propagate waves through the flow. Implementing the LAFPA actuators into a CFD code, however, is another issue.

The LAFPA uses high voltage electronics to rapidly heat the air at multiple locations near the nozzle exit to create the plasma. Electricity is fed to two electrodes periodically causing a spark to jump across the tips and ionize the air forming plasma. The electrodes are recessed in a small cavity to prevent the flow from blowing the spark off before it can heat the air. At this point, there are three primary forces working in the plasma. The electrohydrodynamic (EHD) and magnetohydrodynamic (MHD) forces, which are created by the interactions of charged particles within the plasma, and Joule heating effects, which are created by the rapid heating of air in and around the actuator (Ref. 3). Research shows that the impact of the EHD and MHD forces is limited in high-speed flows and that Joule heating is the primary forcing mechanism in the LAFPA (Ref. 3). Schlieren measurements have supported this conclusion by showing that the shock waves generated by the rapid heating behave similar to small surfaces periodically inserted in the flow (Refs. 4 and 5). Although there are several ways this type of actuator could be modeled in a CFD solver, perhaps the simplest is to stop the solver and reset the flow values in the actuator cavity to simulate the high temperature and pressure created by the actuator. This makes the actuator operate on a time scale that is not resolved by the CFD solver as it turns on and off instantaneously. Temperature was used as the control variable and, based on emission spectroscopy measurements (Ref. 3) and prior simulations (Ref. 6), was set at $\mathrm{T}_{\mathrm{a}}=1000{ }^{\circ} \mathrm{C}$. Further simplifying the model, the temperature and pressure in the actuator are related by the ideal gas law (density is constant because the actuator operates instantaneously so mass can not enter or leave the actuator). While this is a significant assumption as the air in the actuator cavity is not an ideal gas under these conditions, the point 
of these simulations is not to exactly reproduce experimental results but to learn about simulating excited jets. The ideal gas relation is a convenient starting point that can be adjusted in future simulations to more closely replicate an experimental setup.

The nozzle simulated is a simplified version of the nozzle used at OSU (Fig. 1). This geometry was selected because most of the data available with the LAFPA actuators was acquired using this nozzle at OSU. This jet, which has an exit diameter $\left(D_{j}\right)$ of 1 -in., is also relatively small so excitation frequencies around the peak jet instabilities (Stourhal number based on jet diameter, $\mathrm{St}_{\mathrm{Dj}} \approx 0.3$ ) are higher than on a larger jet reducing the number of time steps needed to simulate one cycle. The geometry was simplified by making the external surface of the nozzle a straight line, removing the corners and cavities that would require many grid points to resolve but do not significantly contribute to the solution given the thickness of the nozzle lip. In fact, preliminary simulations indicated that this external surface could be treated as an inviscid wall, removing still more grid points that would be required to resolve a viscous boundary layer, without affecting the flow solution.

The jet conditions for all the baseline (no actuator) and excited jet simulations were run with an acoustic Mach number $\left(\mathrm{M}_{\mathrm{a}}=\mathrm{V}_{\text {jet }} / \mathrm{c}_{\text {ambient }}\right) \mathrm{M}_{\mathrm{a}}=0.9$, cold jet exit flow. These conditions were used to ensure a high-speed, high-energy jet without the added complications of a supersonic jet (i.e., shock cells). Only the axisymmetric azimuthal mode $(\mathrm{m}=0)$ can be excited in a $2-\mathrm{D}$ or axisymmetric simulation, so it was the targeted mode in all the simulations. The excitation frequency used in each case was near the preferred jet frequency of $\mathrm{St}_{\mathrm{Dj}} \approx 0.3$, which is approximately $4 \mathrm{kHz}$ for this nozzle and flow conditions and where the jet should be the most responsive to the actuator perturbations.

(a)
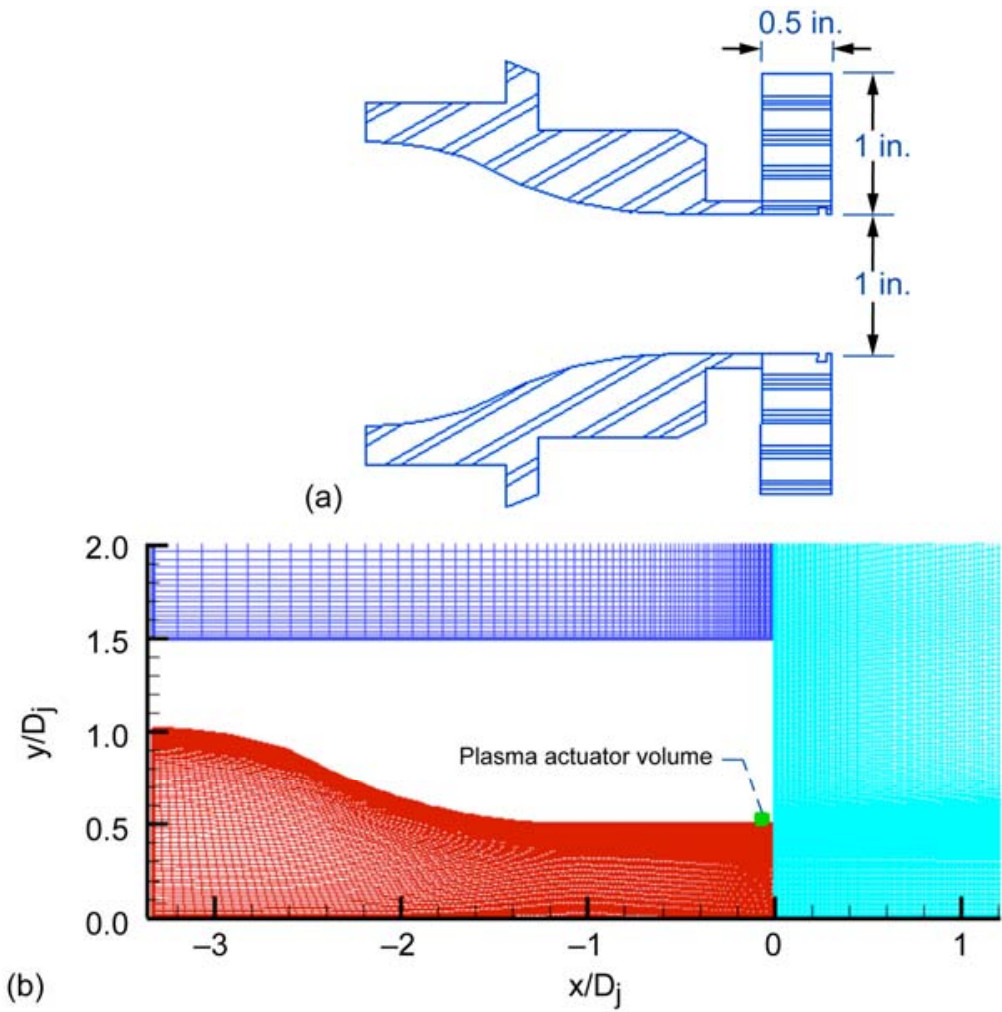

Figure 1.- The nozzle as tested at OSU (a) and the simplified version used in the RANS simulations with the k- $\varepsilon$ and SST turbulence models (b). The DES simulations used the same grid geometry with points added to all blocks. The LES grid used the same surfaces but filleted all the corners (a requirement of the code for viscous flow) and added additional grid points. Note the thick nozzle lip that was required in the experiments to hold the actuator electrodes. 


\section{Solvers and Turbulence Models}

Computational fluid dynamics (CFD) is commonly used to simulate all different kinds of fluid flow. The jet problem combines near wall flow, requiring some resolution of a boundary layer with small time and length scales, and free shear flow, where the large-scale flow structures and turbulent energy dissipation requires both large and small time and length scales. The most complete CFD method, Direct Numerical Simulation (DNS), solves the complete compressible Navier-Stokes equations in threedimensions (3-D) without any modeling assumptions. This requires that all turbulent time and length scales be resolved throughout the flow, necessitating small time steps and very fine grid spacing and effectively limiting the use of DNS to low Reynolds number flows in limited spatial domains. To simulate more realistic problems, assumptions about the flow physics must be made and models applied to cover the regions excluded by these assumptions. Typically, solvers separate the flow into large and small scales, based either on time or space, and assume that the large scales dominate the flow. The large scales are then computed while the small scales are modeled or filtered significantly reducing the required computation time at the expense of some detailed flow information.

The Reynolds Averaged Navier-Stokes (RANS) method separates the flow variables in time into time-averaged (mean flow) and fluctuating (turbulence) parts. The mean flow is then solved directly and the effect of the flow unsteadiness is accounted for by using a turbulence model. Therefore, in a RANS type solver, the turbulence model has the critical role of accounting for all the turbulent unsteady flow energy. In a jet, this means that the turbulence model is responsible for dissipating energy from the largest turbulent eddies down to the fine scale turbulence as the jet mixes with the ambient flow.

A time accurate variant of the RANS method, the Unsteady Reynolds Averaged Navier-Stokes (URANS) method, allows slowly varying unsteadiness, which varies on a much longer scale than the turbulence, to be calculated directly while still modeling the effect of the turbulence. In an excited jet, the turbulence model will also affect the flow unsteadiness created by the actuator and, thereby, the growth and decay of the instabilities input even though the excitation itself will typically be at a time-scale much longer than the turbulence (if it is not, then a URANS solver has very little chance of working since all the flow characteristics would be entirely modeled).

Turbulence models, by design, have a dissipative effect on the mean flow. The best turbulence model for a particular case will greatly depend on the problem being solved and what kind of flow the model was calibrated for. For jet excitation, the turbulence model should be minimally dissipative so as allow the perturbations to grow in the shear layer near the nozzle exit and up to the saturation amplitude for the particular excitation mode, recognizing that at some point the dissipative nature of the turbulence model will retard the perturbation amplitude. This may be acceptable depending on the purpose of the simulation. For example, if a simulation is run to determine the impact of an actuator technology on the jet shear layer immediately after the nozzle exit, then the downstream dissipation of the turbulence model would not be a concern. URANS solvers offer the best combination of accuracy, stability, and speed of any method currently available for most problems. As such, the URANS solver is a good place to start an investigation into simulation methods for excited jets. If this method produces acceptable accuracy in the regions of interest within the jet, then the advantage in computation speed that URANS enjoys over other methods can be used to more efficiently optimize the excitation input.

While URANS CFD solvers are currently the mature simulation methods of choice for most problems, Large Eddy Simulations (LES) are the rapidly developing next generation of flow solvers. LES solvers reduce the solution by separating the flow variables based on space, rather than time, to create a time accurate solution where both the mean and the large-scale fluctuating parts of the flow are captured. The LES methods model or dissipate only the portion of the flow that cannot be resolved based on the mesh spacing (sub-grid scales) and solve directly all of the larger flow scales. This allows the user more direct control over which turbulent flow features are resolved but also generally results in many more grid points and smaller time steps, leading to a significant increase in computational expense, compared to a URANS simulation. The issue of computational expense is particularly acute in problems where there is flow along a surface and some resolution of the viscous boundary layer is necessary. Also, because the 
dissipation is applied to a much smaller portion of the flow, LES simulations tend to be less computationally stable than their URANS counterparts.

The excited jet is necessarily a time dependent problem, a factor that plays to the strength of LES simulations. Additionally, the reduced dissipation from the turbulence model should allow the perturbations to grow and decay in a more realistic manner throughout the jet. However, the need to resolve the viscous boundary layer near the actuator and near the nozzle walls as well as the initial thin shear layer in the developing jet makes LES simulations of excited jets computationally intensive and limits the number of excitation parameters that can be studied. And while the reduced dissipation makes LES more likely to accurately capture the development of the perturbations farther downstream, it also makes the simulation more susceptible to numerical instability caused by sudden changes imparted by certain types of actuators.

A sample from the turbulence models that are commonly used in jet simulations were selected and tested on the excited jet problem. The WIND-US URANS solver represents the currently state of the art in URANS CFD codes. The WIND-US code was developed and is currently maintained by the NPARC Alliance between the NASA Glenn Research Center and the USAF Arnold Engineering Development Center (Refs. 7 to 9). The WIND-US code is a multi-purpose 3-D solver for both the Euler and NavierStokes equations in both steady and unsteady problems, with support for chemically reacting flows. The code also features support for several one-equation, two-equation, and hybrid RANS/LES turbulence models. Two standard two-equation turbulence models, the Chien k- $\varepsilon$ and SST models, and one hybrid RANS/LES turbulence model, the Spalart-DES model, were selected for this study to represent three different approaches to the problem of turbulence modeling and were used with WIND-US so simulate the excited jet.

The NASA Glenn Research Center BASS code was selected as a representative LES code. The BASS code (Refs. 10 and 11) is currently being developed as a general purpose CAA/LES flow solver for compressible flow simulations. The code solves the non-linear Euler and Navier-Stokes equations on generalized curvilinear coordinate grids using the chain rule form of the governing equations. In order to accurately predict the unsteady flow dynamics, high-order spatial differencing methods are combined with optimized explicit time marching schemes. A shock-capturing artificial dissipation scheme with 10th order background dissipation is used to remove unresolved waves form the flow solution (Ref. 12). The BASS development effort has been focused to this point on the prediction of tone and broadband noise from jet engine stators using the inviscid Euler equations (Refs. 13 and 14).

Simulations of an excited jet were run using each turbulence model. Each simulation used either an axisymmetric or 2-D grid to minimize the computation time required for each one. Grid and solver parameters were recorded so that this information can be used in future simulations and the solutions were studied for possible advantages or limitations inherent to each method.

\section{Chien k- $\varepsilon$ Model}

The Chien k- $\varepsilon$ was selected as a standard two-equation model (Refs. 15 and 16). This model was added to WIND-US as a robust and stable k- $\varepsilon$ model suitable for a variety of flows. The model features stability enhancements in the form of limiters that cap the turbulence quantities, relaxation to increase stability at start-up, and a correction for adverse pressure gradient flows. The WIND-US implementation also offers the option of the Sarkar and Wilcox compressibility corrections. All options were held to default values for these simulations and neither the Sarkar nor Wilcox compressibility corrections were used. Although these coefficients may be adjusted to improve the results, the default values should give a reasonable idea of the model behavior while avoiding the large number of simulations that would be required to fully investigate each parameter.

The Chien model was tested with the standard WIND-US second-order Roe upwind scheme modified for stretched grids and employing a TVD flux limiter. The MacCormack DQ limiter (Ref. 17), which is available in WIND-US and commonly used to speed convergence in steady flows, was disabled after early trials showed that it limited the growth of the actuator perturbations. First-order implicit time 
marching was used, with the default parameters, and a constant time step of $100 \mathrm{~ns}$ was found to be the upper limit for stability throughout the cycle. The computational time per time step ranged from 0.45 to $0.60 \mathrm{sec}$ using 14-processors on a local computer cluster and the grid had approximately 275,000 points. The grid was refined to show the grid independence of the solution.

Although the Chien k- $\varepsilon$ model as implemented in WIND-US features stability enhancements, it was unstable at the start of each actuator cycle. It is noted in the WIND-US manual that a different turbulence model may be required to initialize the turbulence before the Chien k- $\varepsilon$ model is used (Ref. 9). Each actuator cycle, therefore, was started using the SST turbulence model for the equivalent of one time step. Once the turbulence was initialized, the k- $\varepsilon$ model was stable and able to complete the cycle. This process added a considerable amount of work for the user and is a drawback to using this model in cyclical problems such as jet excitation.

\section{Menter SST Model}

A relative of the k- $\varepsilon$ turbulence model, the Menter SST (Ref. 18) blends the k- $\omega$ model of Wilcox in the near wall and boundary layer regions with a standard k- $\varepsilon$ model in the free stream and free shear regions by reformulating the $\mathrm{k}-\varepsilon$ model into the $\mathrm{k}-\omega$ form. This adds stability in the near wall region compared to a standard k- $\varepsilon$ model and, in fact, it is recommended in the WIND-US manual that the SST model be used to initialize the turbulence before the Chien k- $\varepsilon$ model is used (Ref. 9). It has also been documented that the SST model is the most complete choice for simulating jet flows with WIND-US (Refs. 19 and 20). All coefficients and parameters for the SST model were kept to their default values.

The SST model, like the Chien k- $\varepsilon$ model, was used with the standard WIND-US second-order Roe upwind scheme modified for stretched grids with the TVD flux limiter but without the MacCormack DQ limiter. First-order implicit time marching was used and grid refinement showed the grid independence of the solution. Also like the Chien k- $\varepsilon$ model, a maximum time step of $100 \mathrm{~ns}$ was used for stability throughout the cycle. Time steps were also completed slightly faster, at between 0.35 and $0.40 \mathrm{sec}$ on average, than recorded for the $\mathrm{k}-\varepsilon$ model using the same 14-processors system.

\section{Spalart-DES Model}

The Spalart-DES model was developed to overcome some the computational limitations of LES in near wall and boundary layer flows while retaining the accuracy of a LES simulation in the free stream (Refs. 21 and 22). The one-equation Spalart-Allmaras turbulence model is used exclusively in the near wall region. In the free stream region, the Spalart-Allmaras model implicitly reduces to a sub-grid-scale model to deal with the flow not directly calculated on the grid. This allows the transition to LES to occur implicitly, controlled by one parameter, rather than forcing the user to explicitly declare zones.

The model uses the same second-order Roe scheme in space as the other WIND-US simulations (the Spalart-DES model was developed with a fourth-order central difference scheme but this Roe scheme was used because it is the default in WIND-US). A first-order implicit scheme is used for time marching. Again, all parameters were left unchanged from the default values and the time step was held at $100 \mathrm{~ns}$ for stability. A second-order time marching scheme available in WIND-US was tested with the Spalart-DES model but found to be unstable when the actuators where enabled. This reduction in stability is due to the lower dissipation inherent in the second-order scheme. Topologically, the grid used for the DES simulations was identical to the grid used for the other WIND-US simulations. Also like the other WIND-US simulations, the DES simulations were run using the axisymmetric assumption. The number of grid points, however, was increased in both the $\mathrm{x}$ and $\mathrm{y}$-directions away from the nozzle, to total approximately 1.9 million points, because the DES simulations need to resolve smaller turbulent length scales that are modeled in both the SST and k- $\varepsilon$ simulations. As expected, the increased grid density resulted in an increase in computation time, to between 2.10 and $2.25 \mathrm{sec}$ per time step using 24processors on the computer cluster (10 processors more than the previous simulations). 


\section{LES}

The BASS CAA/LES solver was used to simulate the excited jet test case as a fully time accurate alternative to the URANS simulations. The BASS code solved the filtered Navier-Stokes equations, in 2-D, using an Implicit LES (ILES) strategy (Ref. 23), in which the 10th order artificial dissipation model in the code is used to filter the sub-grid turbulence scale. The HALE-RK67 explicit time marching scheme (Ref. 24) was used with the Tam and Webb optimized fourth-order DRP spatial differencing scheme (Ref. 25) for these simulations. At the outer edges for the computational domain, the Thompson boundary conditions (Refs. 26 and 27) were combined with sponge layers (Ref. 28) to prevent reflections from reentering the domain.

An entirely new grid was required for the BASS simulations. The BASS code has been developed with several automatic parallelization features that require the grid to have full face block to block matching, resulting in a grid with 506 blocks. BASS also requires more grid points in the viscous boundary layer along the nozzle wall, and particularly at near the actuator walls, than any of the WINDUS simulations for numerical stability. The grid also included both sides of the jet, rather than only one side with a symmetry boundary condition along the nozzle centerline as run in the WIND-US simulations, to improve the simulation along the centerline. The grid was stretched away from the nozzle in the axial and radial directions, especially past $x / D_{j}=10$ where the flow was not studied resulting in a grid that contained only approximately 215,000 points. And while this is the smallest grid by number of points tested, BASS still required around $4 \mathrm{sec}$ per time step using 17 processors on the computer cluster, the longest of any simulation. In order to decrease the total time required to compute one actuator cycle while maintaining stability, the time step was changed during the cycle. The maximum stable time step was $0.75 \mathrm{~ns}\left(7.5 \times 10^{-10} \mathrm{sec}\right)$ from the start of a cycle until the actuator flow passed the nozzle exit. The time step could then be raised to $3.75 \mathrm{~ns}\left(3.75 \times 10^{-9} \mathrm{sec}\right)$ for the remainder of the cycle.

Note that BASS is still in development and work is ongoing to streamline the code and make it more efficient, particularly in the area of parallelization and the associated message passing. An AdamsBashforth multi-time-stepping scheme is also being added to reduce the computation required per time step (Ref. 29).

\section{Simulation Results}

Simulations of a baseline (unexcited, no actuator) jet were conducted using URANS and LES CFD codes to establish the jet flow before the actuators were added. These baseline results, shown in Figure 2, were computed by allowing the simulation to reach a converged solution while the DES and LES mean flows were computed by time averaging a series of instantaneous flow fields. These plots show the SST simulation results in a longer jet potential core than the k- $\varepsilon$ simulation, which is consistent with past results (Ref. 30). The DES and LES results show an even shorter high-speed region compared to the k- $\varepsilon$ results although the flow in the DES simulation continues along the jet axis at a relatively high speed. This may be caused by the hybrid URANS/LES nature of the DES model (not having quite the right balance between a pure RANS turbulence model and a LES sub-grid model) and the axisymmetric assumption, which prevents the flow structures from breaking up in the azimuthal direction. The DES results also show a jet that spreads slower than the other models while the LES shows a jet spreading faster than observed in the other results though this behavior may be grid dependent. It is worth reiterating here that caution should be used before drawing any firm conclusions using either the DES axisymmetric or the LES 2-D simulations. Large-scale turbulent structures, which both methods calculate directly, are inherently 3-D and need to be computed as such. The information gleaned from analyzing the results of these 2-D simulations will only serve to guide future 3-D simulations.

Once the baseline flow is computed, the actuator is introduced into the flow. Figure 3 shows the density of the flow in the actuator region $20 \mu \mathrm{s}$ after the beginning of the actuator cycle. The LAFPA type actuator was expected to generate a shock wave that perturbs the flow, which is observed in the density 

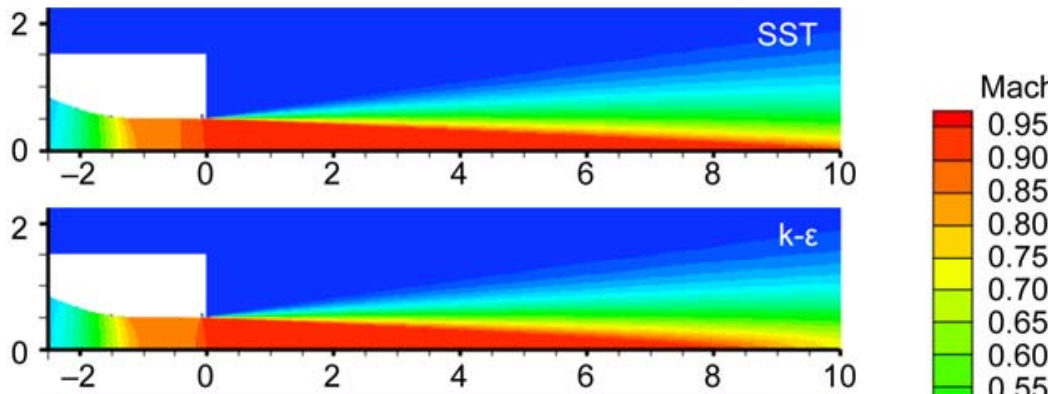

0.80

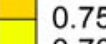

0.70

0.65

0.60

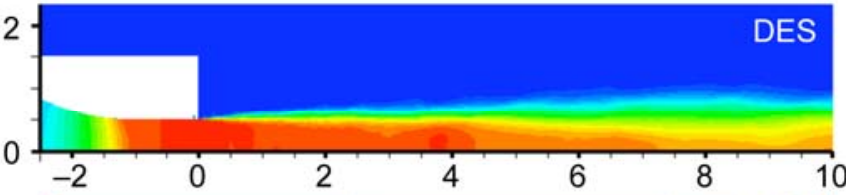

0.55

0.50

0.45

0.40

0.35

0.30

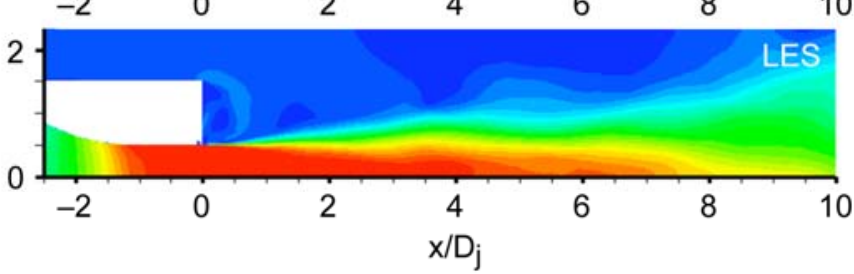

0.25

0.20

0.15

0.10

0.05

Figure 2.-Mach number for the baseline (no actuator) flow. The SST and k- $\varepsilon$ results show converged steady flows. The DES and LES results were determined by time averaging many instantaneous flow results. The range in the axial direction is limited to only cover the range of interest in the excited jet.
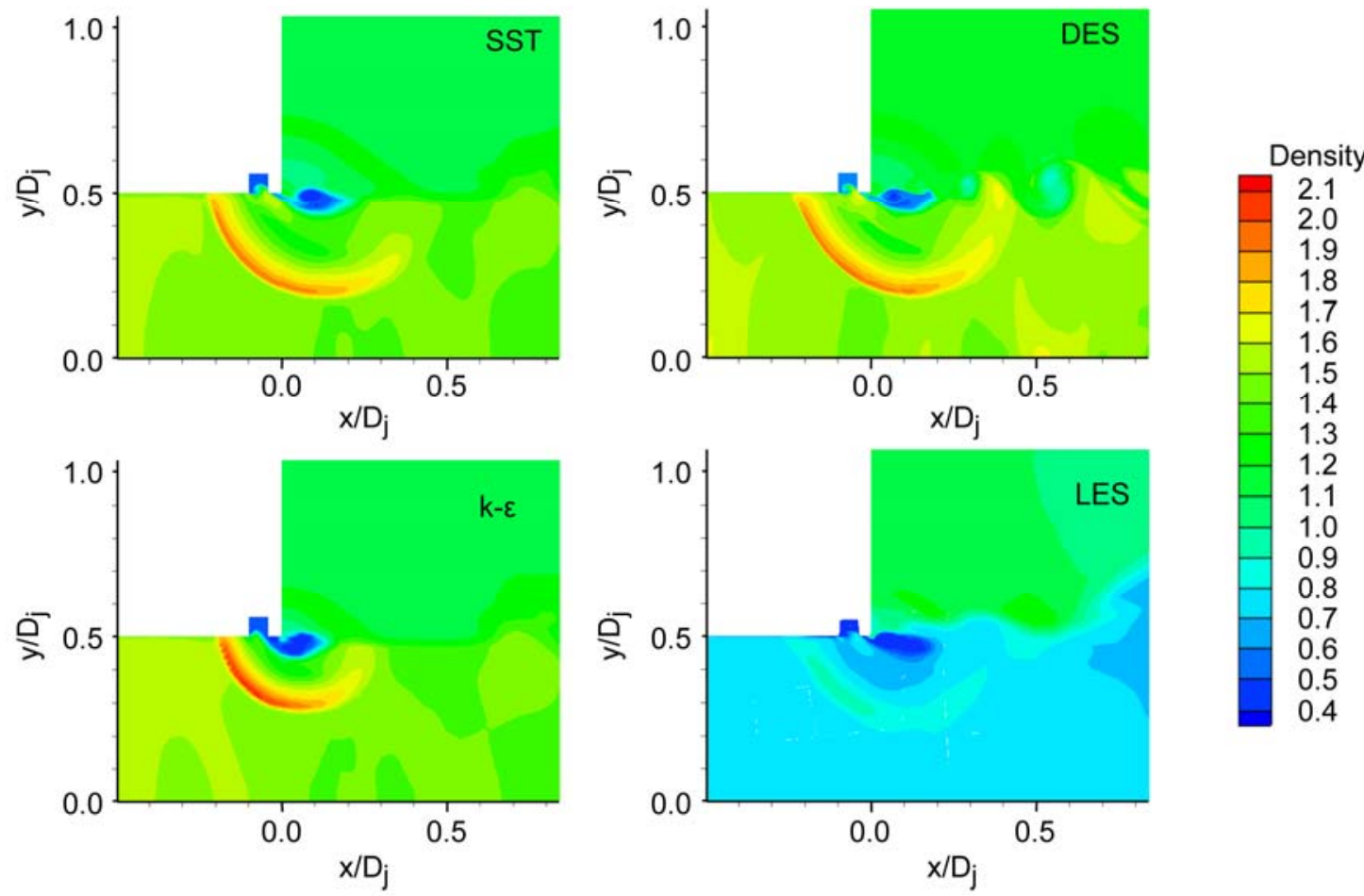

Figure 3.-Density near the actuator and nozzle lip $20 \mu$ s after the actuator is activated. The LES simulation has a different stagnation temperature upstream at the nozzle exit leading to the variation in density. 
plot from all the simulations. The wave leaves the actuator cavity with sufficient power to cause the flow to separate from the nozzle surface right at the nozzle exit as the jet flow is forced around the pressure wave, behavior which is consistent with the expected mechanism behind the LAFPA. The flow separation sets up a vortical flow structure that will travel downstream and affect the development of the jet; however, the effect that this structure has on the jet will be strongly affected by the turbulence model.

The instantaneous vorticity throughout the flow at the end of the actuator cycle for each simulation is shown in Figure 4. Both the SST and k- $\varepsilon$ models support the initial vortex created by the actuator but do not allow it to develop, damping it out around $\mathrm{x} / \mathrm{D}_{\mathrm{j}}=1$. The DES model allows the vortex to propagate downstream and grow with minimal loss of energy, which is expected from an approach that is designed to capture the large-scale unsteady flow dynamics directly. The axisymmetric assumption applied in the DES simulations also disrupts the energy cascade, an inherently 3-D processes where large-scale structures break down into smaller structures before energy is dissipated by viscous forces, by preventing the flow from moving in the azimuthal direction. The LES also shows the propensity to propagate the vortex, with vorticity appearing up to $\mathrm{x} / \mathrm{D}_{\mathrm{j}}=4$, but the structures are not as sharp as those found in the DES results and do not persist downstream. This strongly suggests that the LES grid is too coarse in this region and, therefore, is dissipating rather than calculating the smaller turbulent scales needed to support these vortices.

The unsteady flow dynamics that may be resolved in a DES or LES simulation is determined by the grid spacing and the numerical scheme employed. Every numerical scheme requires some number of points to get an accurate spatial derivative and, thus, and accurate time derivative. The DRP scheme in BASS requires approximately 6 grid points per wavelength for a simple harmonic disturbance. The second-order Roe method used in the DES simulations needs on the order of 40 grid points to resolve the same disturbance and propagate the waves at the correct speed (the waves will propagate with fewer points but at an incorrect speed). In both case, more grid density is required to resolve any non-linear flow

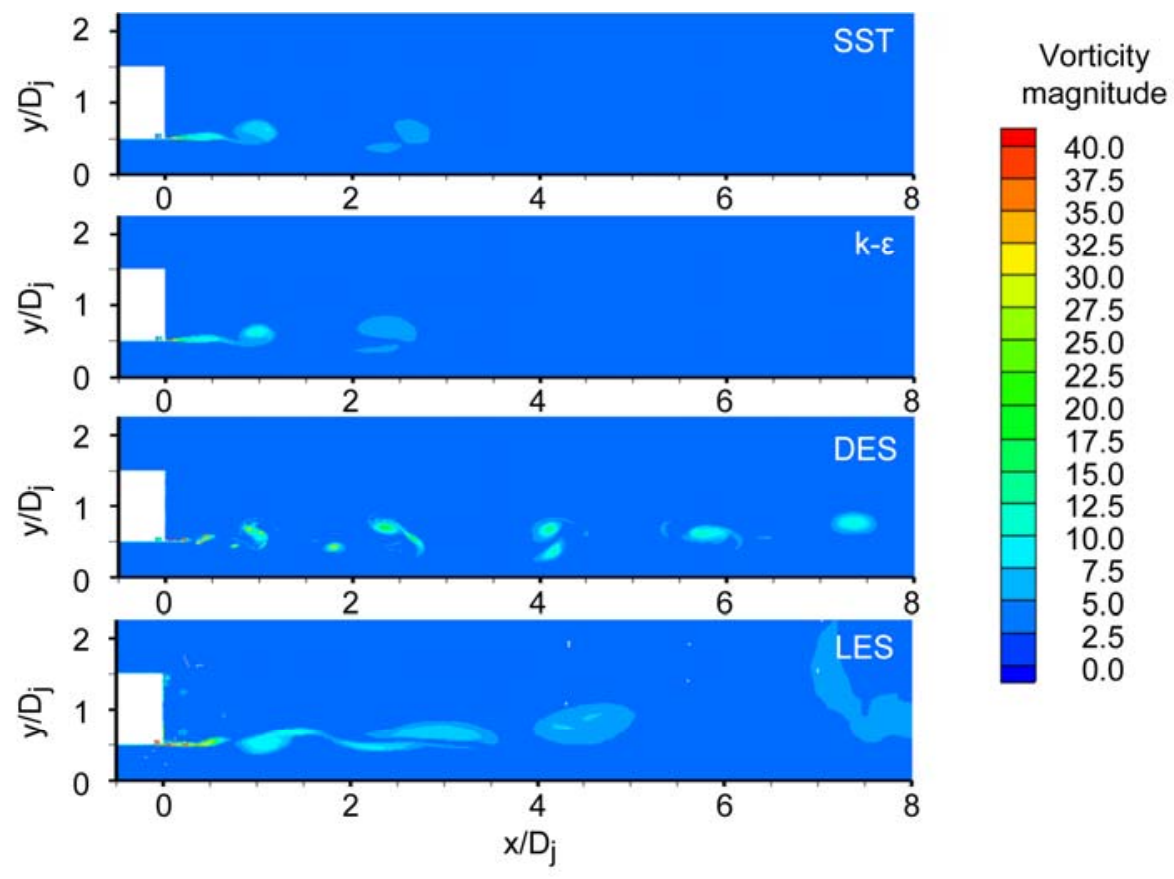

Figure 4.-Vorticity magnitude calculated using the WIND-US URANS code with the SST, $\mathrm{k}-\varepsilon$, and Spalart-DES turbulence models and calculated using the BASS LES code. 

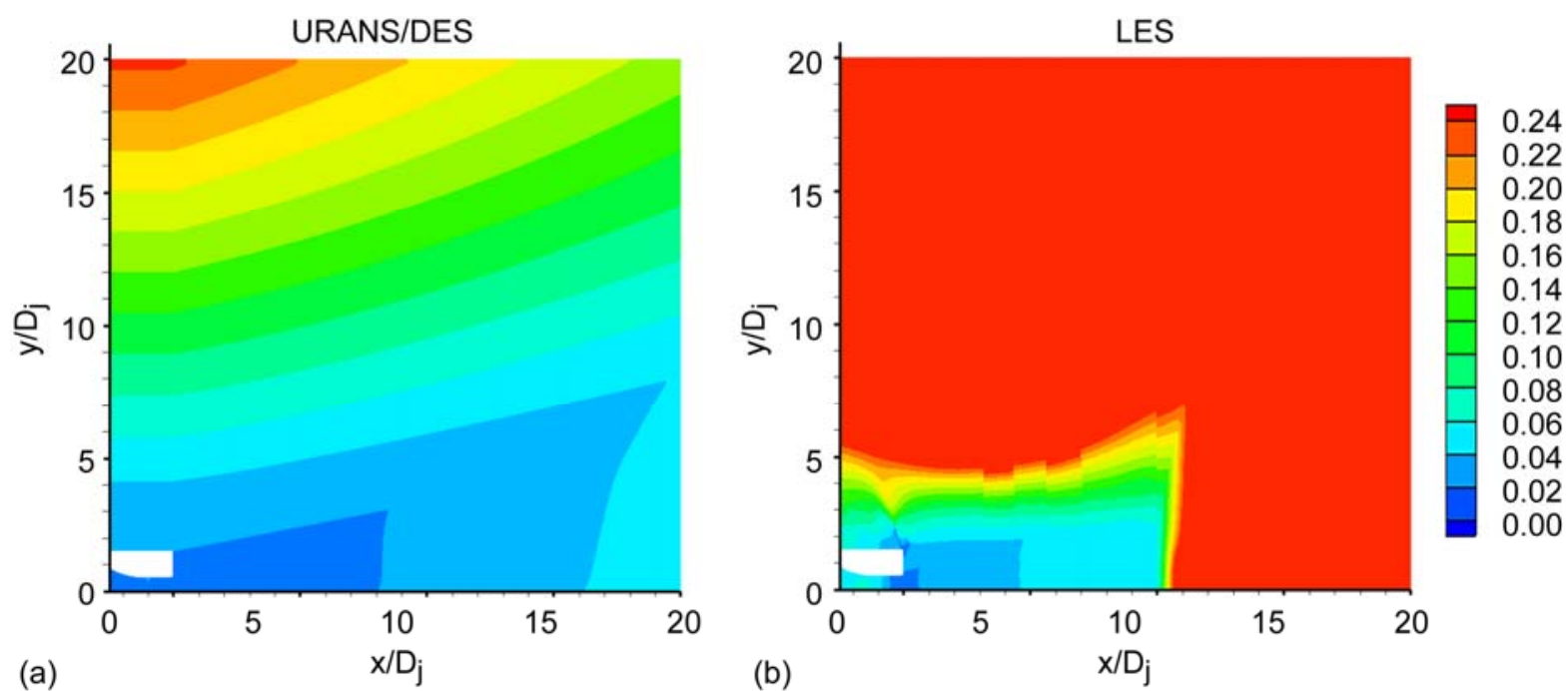

Figure 5.-Grid spacing for the DES (a) and LES (b) simulations. Grid spacing is defined as the maximum of $\Delta x$ and $\Delta y$ at each point and contour levels are nondimensionalized by the jet diameter $\left(L=\right.$ maximum $\left.(\Delta x, \Delta y) / D_{j}\right)$.

dynamics that may be present. Any turbulence small than the minimum grid spacing is dissipated resulting in the smearing and loss of the flow structure. Figure 5 shows the density of the grids used for the DES and LES simulations, where the grid density was defined as the maximum of $\Delta \mathrm{x}$ and $\Delta \mathrm{y}$ at each point. The DES grid has a significant number of additional grid points in the near nozzle region than the LES grid. This increases the grid density on the DES grid enough to overcome the additional number of points required by 2 nd-order Roe scheme. The LES grid stretches quickly in the radial direction outside the nozzle and downstream, especially past $x / D_{j}=10$, to reduce the total number of points and reduce the computation time. The difference between the LES and DES vorticity results (Fig. 4) and a comparison of the grid, however, indicates that the LES grid stretches too quickly. A much finer grid, on the order of the DES grid, should significantly improve the LES results and should be used for future LES simulations.

A vortex forms at the nozzle exit in response to the flow separation created by the actuator. That vortex propagates downstream and is either supported or dissipated at different levels by the CFD method used in the simulation. These observations, while insightful, are not easily compared qualitatively to the available experimental data. And although the there is little point in trying to quantitatively reproduce these results, a qualitative comparison may be instructive. Researchers at OSU have recorded pressure fluctuations, as a function of time, at several axial stations at the jet lipline $\left(y / D_{j}=0.5\right)$. After computing a Fourier transform, this data shows the axial growth and decay of the actuator perturbation by extracting only the pressure fluctuations at the actuator frequency. Similar data, sampled over one actuator cycle, can be extracted from the time accurate simulation data recorded using each of the turbulence models once a sufficient number of cycles have been run to initialize the flow (the minimum was found to be approximately 8 cycles to extract data up to $\mathrm{x} / \mathrm{D}_{\mathrm{j}} \approx 10$ ).

The numerical results for each simulation is are compared to the experimental data in Figure 6 . Note that the experimental data is amplitude shifted so that any comparison of absolute amplitudes invalid. However, the perturbation growth rate, peak location, and decay rate are useful and can be compared to the experimental data for each scheme. The results shown in Figure 6 indicate that all of the simulation methods have some limitations. The pure URANS simulations using the SST and k- $\varepsilon$ turbulence models have an initial growth rate similar to the experimental data over the first $x / D_{j} \approx 1.0$ from the nozzle exit. The jet response determined using SST model then flattens out and decays far short of the experimental peak location at $\mathrm{x} / \mathrm{D}_{\mathrm{j}} \approx 2.5$. The jet response using the Chien $\mathrm{k}-\varepsilon$ model, however, continues to grow, although more slowly, and peaks around $\mathrm{x} / \mathrm{D}_{\mathrm{j}} \approx 2$ before decaying rapidly. In both cases, the rate at which the perturbation decays far exceeds the rate measured in the experiment, a result that is not surprising based on the models propensity to dissipate the downstream flow structures. 


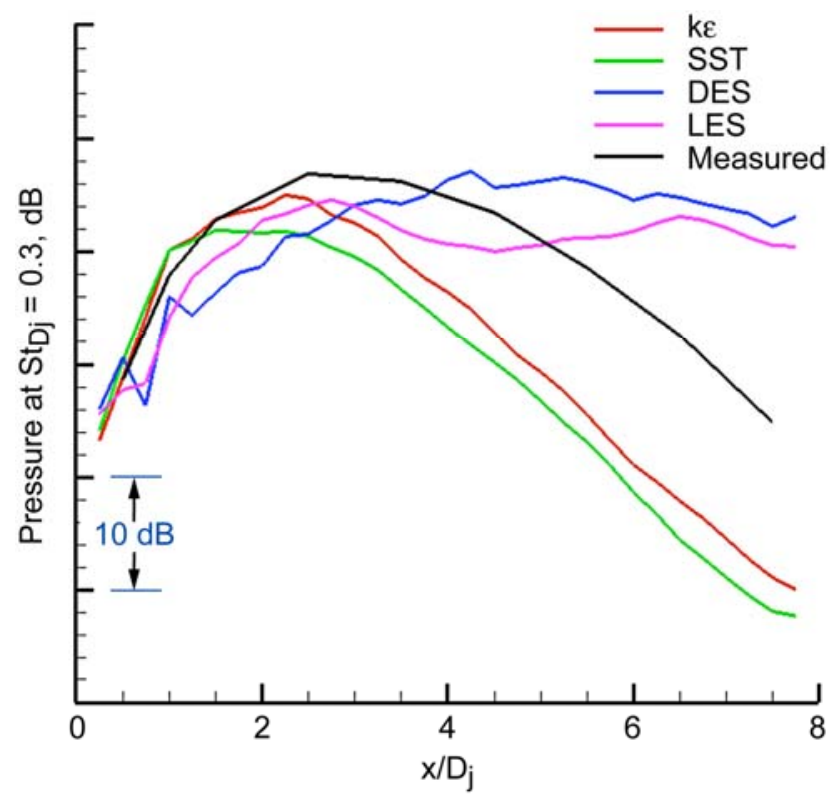

Figure 6.-Axial growth and decay of pressure fluctuations at the actuator input frequency $\left(\mathrm{St}_{\mathrm{Dj}} \approx 0.3\right)$ compared to experimental data acquired at OSU (Ref. 1). Note that the experimental data has been shifted in amplitude and, therefore, any comparison of absolute amplitude is invalid.

Unlike the pure URANS turbulence models, the jet response simulated using the Spalart-DES hybrid URANS/LES model has the slowest initial growth rate. It also places the peak jet response the farthest downstream, around $\mathrm{x} / \mathrm{D}_{\mathrm{j}} \approx 4$ or $\mathrm{x} / \mathrm{D}_{\mathrm{j}} \approx 1.5$ downstream of the measured peak location and allows the perturbation to continue downstream almost undamped. While it is not surprising that the DES model, especially in an axisymmetric simulation, does not dissipate the perturbation like the pure URANS simulations, it is somewhat surprising that the initial growth rate is not closer to the experimental, SST, or $\mathrm{k}-\varepsilon$ results. It is possible that the Spalart-Allmaras RANS turbulence model, operating in the near wall region, is over damping the initial perturbation and, in effect, reducing the strength of the actuator perturbation. If this is the case, varying the constant that controls the size of RANS region should change the jet response. However, as the authors of this model note, the value of this constant has little effect in 2-D simulations and needs to be set using 3-D simulations (Ref. 21).

Finally, the LES simulation, using the BASS code, calculates a jet response somewhere between the other simulations. The initial growth rate, while faster than the DES simulations, is slower than the SST, $\mathrm{k}-\varepsilon$, and experimental data. The response, however, continues to grow and has a peak near the peak response location measured in the experiments. A short amplitude decrease is followed by a period of generally flat response where the response would be expected to decay based on the experimental data. As was the case in the DES simulations, these persistent levels are expected in a 2-D LES simulation because the flow structures are not permitted to decay in the azimuthal direction. LES, because it is filtered in space rather than time, is heavily dependent on the grid spacing and, based on the vorticity data and length scale map, it is likely that the grid stretches too far too close to the nozzle exit to support the additional growth rate measured in the experiment.

The jet response determined at the nozzle lipline is an easily measured metric in an experiment where time and equipment limits the number of data points available. One of the strengths of CFD is the ability to sample the entire flow field at any desired interval. Figure 7 shows pressure, recorded at the end of an actuator cycle from simulations using each of the turbulence models, to support the previous comparisons 

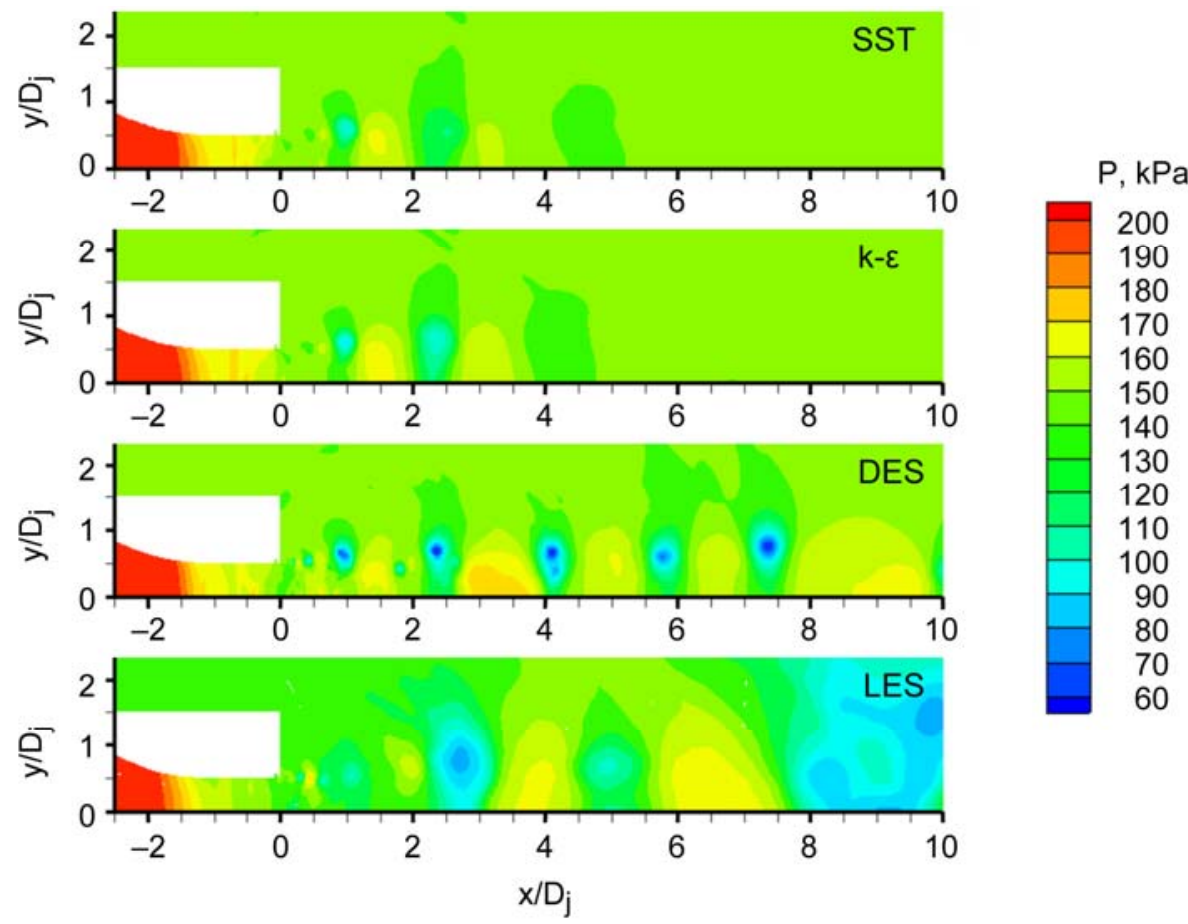

Figure 7.-Pressure determined using each turbulence model at the end of an actuator cycle.

from only along the jet lipline. Note that in the URANS simulations, the pressure fluctuations are entirely due to the actuator because all the natural flow unsteadiness is modeled. The DES and LES results, however, contain pressure fluctuations from the turbulence in the jet as well and the actuator. First, the damping of all flow structures by the SST and k- $\varepsilon$ turbulence models is observed by $x / D_{j} \approx 5$. The flow fields from the DES and LES, by comparison, show vortices traveling to the end of the domain, which is expected based on the slow perturbation decay rates observed previously. The data also shows differences between the DES and LES simulations. The DES simulation shows well defined vortices interacting at various points in the flow field (e.g., the two vortices at $\mathrm{x} / \mathrm{D}_{\mathrm{j}} \approx 4$ ). In the LES simulation data, however, the flow structures are fuzzy and the interaction is not captured in the flow field. This difference shows the need for tighter grid spacing in the LES simulation, which, in theory, will capture these flow features given enough grid.

\section{Conclusions}

Jet excitation has many applications ranging from noise reduction to enhanced plume mixing. Computational fluid dynamics (CFD) can be used to research and optimize the excitation input, reducing the number of experiments required and, thus, the cost to develop the technology. CFD, however, is a viable option only if a suitable simulation method can be found.

A series of simulations studied the advantages and disadvantages of four different turbulence models for a jet excitation problem with the goal of guiding future simulations. The results indicated that pure URANS turbulence models fall short of the expected results. The URANS/LES hybrid model, in the form of the Spalart-DES model, has potential, based on both computation speed and flow results, and should be investigated in the future using full 3-D simulations. Furthermore, these simulations should begin with a study of the impact that the size of the URANS region has on the initial growth rate of the perturbations, which is the biggest unknown in this hybrid method and which may significantly alter the initial perturbation growth rate. The LES simulations also showed potential based on the flow data and should also be continued using full 3-D simulations with a finer spaced grid (on the order of the DES grid). The 
biggest drawback to the LES simulations is the computation time required, but this should be greatly reduced by improvements in the efficiency of the code as it is developed. Ultimately, future simulations of excited jets will benefit from the knowledge and experience gained through these simplified simulations.

\section{References}

1. Samimy, M., Kim, J.-H., Kastner, J., Adamovich, I., and Utkin, Y., "Active control of a Mach 0.9 Jet for Noise Mitigation Using Plasma Actuators,” AIAA J., Vol. 45(4), 890-901, 2007.

2. Samimy, M., Kim, J.-H., Kastner, J., Adamovich, I., and Utkin, Y., “Active control of high-speed and high-Reynolds number jets using plasma actuators," J. Fluid Mech., Vol. 578, 305-330, 2007.

3. Utkin, Y., Keshav, S., Kim, J.-H., Kastner, J., Adamovich, I., and Samimy, M., "Development and Use of Localized Arc Filament Plasma Actuators For High-speed Flow Control," J. of Physics D: Applied Physics, 40, 685-694, 2007.

4. Leonov, S., Bityurin, V., Savelkin, K., and Yarantsev, D., "Effect of Electrical Discharge on Separation Processes and Shock Position in Supersonic Airflow," AIAA 2002-0355, 40th AIAA Aerospace Sciences Meeting and Exhibit, 14-17 January 2002, Reno, NV.

5. Leonov, S., Bityurin, V., and Yarantsev, D., "The Effect of Plasma Induced Separation," AIAA 2003-3853, 34th AIAA Plasmadynamics and Lasers Conference, 23-26 June 2003, Orlando, FL.

6. Brown, C., "Scalability of the Localized Arc Filament Plasma Actuators," AIAA 2008-3043, 14th AIAA/CEAS Aeroacoustics Conference, 5-7 May 2008, Vancouver, Canada.

7. Bush, R., Power, G., and Towne, C., "WIND: The Production Flow Solver of the NPARC Alliance," AIAA 1998-0935, 1998.

8. Nelson, C. C. and Power, G. D., "CHSSI Project CFD-7: The NPARC Alliance Flow Simulation System," AIAA 2001-0594, 2001.

9. The Wind User's Guide, User Manual, The NPARC Alliance, http://www.grc.nasa.gov/WWW/winddocs/user/index.html

10. Hixon, R., Nallasamy, M., and Sawyer, S., "Parallelization Strategy for an Explicit Computational Aeroacoustics Code," AIAA 2002-2583, July 2002.

11. Hixon, R., Nallasamy, M., Sawyer, S., and Dyson, R., "Comparison of Numerical Schemes for a Realistic Computation Aeroacoustics Problem," International Journal of Aeroacoustics, Vol. 3, pp. 379-397, 2004.

12. Hixon, R., Bhate, D., Nallasamy, M., and Sawyer, S., "Shock-Capturing Dissipation Schemes for High-Accuracy Computational Aeroacoustics (CAA) Codes," AIAA 2006-2413, May 2006.

13. Hixon, R., Nallasamy, M., and Sawyer, S., "Progress towards the prediction of turbomachinery noise using Computational Aeroacoustics," Inter-Noise paper IN06-116, Dec. 2006.

14. Nallasamy, M., Hixon, R., and Sawyer, S., "Solution of unsteady Euler equations: Gust-cascade interaction tones," Computers and Fluids, Vol. 36, pp. 724-741, 2007.

15. Chien, K.Y., "Prediction of Channel and Boundary-Layer Flows with a Low-Reynolds-Number Turbulence Model," AIAA J., Vol. 20(1), pp. 33-38, 1982.

16. Yoder, D.A. and Georgiadis, N.J., "Implementation and Validation of the Chien k- $\varepsilon$ Turbulence Model in the WIND Navier-Stokes Code," AIAA 1999-0745, 37th AIAA Aerospace Sciences Meeting and Exhibit, 11-13 January 1999, Reno, NV.

17. MacCormack, R.W., "Considerations for Fast Navier-Stokes Solvers," presented at the conference on Advances of Flow Simulation Techniques, Davis, CA, May 1997.

18. Menter, F.R., "Two-Equation Eddy-Viscosity Turbulence Models for Engineering Applications," AIAA J., Vol. 32(8), pp. 1598-1605, August 1994.

19. Georgiadis, N. and Papamoschou, D., "Computational Investigations of High-Speed Dual-Stream Jets," AIAA 2003-3311, 2003.

20. Georgiadis, N.J., Rumsey, C.L., Yoder, D.A., and Zaman, K.B.M.Q., "Effects of RANS Turbulence Modeling on Calculation of Lobed Nozzle Flowfields," AIAA 2003-1271, 2003. 
21. Spalart, P.R., Jou, W.H., Strelets, M., and Allmaras, S.R., "Comments on the Feasibility of LES for Wings, And on a Hybrid RANS/LES Approach," First AFOSR International Conference On DNS/LES, August 4-8, 1997, Ruston, LA. (In Advances in DNS/LES, Liu, C. and Liu, Z., eds., Greyden Press, Columbus OH.)

22. Shur, M., Spalart, P.R., Strelets, M., and Travin, A., "Detached-Eddy Simulation of an Airfoil at High Angle of Attack," 4th International Symposium on Engineering Turbulence Modeling and Measurements, May 24-26 1999, Corisca.

23. Grinstein, F., Drikakis, D., Fureby, C., and Youngs, D., "Transition and Turbulence Decay in the Taylor-Green Vortex," AIAA 2006-0698, January 2006.

24. Hixon, R., Allampali, V., Nallasamy, M., and Sawyer, S., "High-Accuracy Large-Step Explicit Runge-Kutta (HALE-RK) Schemes for Computational Aeroacoustics," AIAA 2006-0797, January 2006.

25. Tam, C.K.W. and Webb, J.C., "Dispersion-relation-preserving finite-difference schemes for computational acoustics," J. of Computational Physics, Vol. 107, pp. 262-281, 1993.

26. Thompson, K.W., "Time dependent boundary conditions for hyperbolic systems," J. of Computational Physics, Vol. 68, pp. 1-24, 1987.

27. Thompson, K.W., "Time dependent boundary conditions for hyperbolic systems II," J. of Computational Physics, Vol. 89, pp. 439-461, 1990.

28. Goodrich, J., "A Comparison of Three PML Treatments for CAA (and CFD)," AIAA 2008-2922, May 2008.

29. Allampali, V. and Hixon, R., "Implementation of Multi-Time Step Adams-Bashforth Time Marching Schemes for CAA," AIAA 2008-0029, January 2008.

30. Georgiadis, N.J., Yoder, D.A., and Engblom, W.A., "Evaluation of Modified Two-Equation Turbulence Models for Jet Flow Predictions," AIAA J., Vol. 44(12), pp. 3107-3114, December 2006. 


\begin{tabular}{|c|c|c|}
\hline \multicolumn{2}{|c|}{ REPORT DOCUMENTATION PAGE } & $\begin{array}{l}\text { Form Approved } \\
\text { OMB No. 0704-0188 }\end{array}$ \\
\hline \multicolumn{3}{|c|}{$\begin{array}{l}\text { The public reporting burden for this collection of information is estimated to average } 1 \text { hour per response, including the time for reviewing instructions, searching existing data sources, gathering and maintaining the } \\
\text { data needed, and completing and reviewing the collection of finformation. Send comments regarding this burden estimate or any other aspect of this collection of information, including suggestions for reducing this } \\
\text { burden, to Department of Defense, Washington Headquarters Services, Directorate for Information Operations and Reports (0704-0188), 1215 Jefferson Davis Highway, Suite } 1204 \text {, Arlington, VA } 222202-4302 \text {. } \\
\text { Respondents should be aware that notwithstanding any other provision of law, no person shall be subject to any penalty for failing to comply with a collection of information if it does not display a currently valid OMB } \\
\text { control number. } \\
\text { PLEASE DO NOT RETURN YOUR FORM TO THE ABOVE ADDRESS. }\end{array}$} \\
\hline $\begin{array}{l}\text { 1. REPORT DATE (DD-MM-YYYY) } \\
01-09-2010\end{array}$ & $\begin{array}{l}\text { 2. REPORT TYPE } \\
\text { Technical Memorandum }\end{array}$ & 3. DATES COVERED (From - To) \\
\hline \multirow{3}{*}{\multicolumn{2}{|c|}{$\begin{array}{l}\text { 4. TITLE AND SUBTITLE } \\
\text { Effect of Turbulence Modeling on an Excited Jet }\end{array}$}} & 5a. CONTRACT NUMBER \\
\hline & & 5b. GRANT NUMBER \\
\hline & & 5c. PROGRAM ELEMENT NUMBER \\
\hline \multirow{3}{*}{\multicolumn{2}{|c|}{$\begin{array}{l}\text { 6. AUTHOR(S) } \\
\text { Brown, Clifford, A.; Hixon, Ray }\end{array}$}} & 5d. PROJECT NUMBER \\
\hline & & 5e. TASK NUMBER \\
\hline & & $\begin{array}{l}\text { 5f. WORK UNIT NUMBER } \\
\text { WBS 984754.02.07.03.17.03 }\end{array}$ \\
\hline \multicolumn{2}{|c|}{$\begin{array}{l}\text { 7. PERFORMING ORGANIZATION NAME(S) AND ADDRESS(ES) } \\
\text { National Aeronautics and Space Administration } \\
\text { John H. Glenn Research Center at Lewis Field } \\
\text { Cleveland, Ohio 44135-3191 }\end{array}$} & $\begin{array}{l}\text { 8. PERFORMING ORGANIZATION } \\
\text { REPORT NUMBER } \\
\text { E-17393 }\end{array}$ \\
\hline \multirow{2}{*}{\multicolumn{2}{|c|}{$\begin{array}{l}\text { 9. SPONSORING/MONITORING AGENCY NAME(S) AND ADDRESS(ES) } \\
\text { National Aeronautics and Space Administration } \\
\text { Washington, DC 20546-0001 }\end{array}$}} & $\begin{array}{l}\text { 10. SPONSORING/MONITOR'S } \\
\text { ACRONYM(S) } \\
\text { NASA }\end{array}$ \\
\hline & & $\begin{array}{l}\text { 11. SPONSORING/MONITORING } \\
\text { REPORT NUMBER } \\
\text { NASA/TM-2010-216768 }\end{array}$ \\
\hline \multicolumn{3}{|c|}{$\begin{array}{l}\text { 12. DISTRIBUTION/AVAILABILITY STATEMENT } \\
\text { Unclassified-Unlimited } \\
\text { Subject Category: } 71 \\
\text { Available electronically at http://gltrs.grc.nasa.gov } \\
\text { This publication is available from the NASA Center for AeroSpace Information, 443-757-5802 }\end{array}$} \\
\hline
\end{tabular}

\section{SUPPLEMENTARY NOTES}

\section{ABSTRACT}

The flow dynamics in a high-speed jet are dominated by unsteady turbulent flow structures in the plume. Jet excitation seeks to control these flow structures through the natural instabilities present in the initial shear layer of the jet. Understanding and optimizing the excitation input, for jet noise reduction or plume mixing enhancement, requires many trials that may be done experimentally or computationally at a significant cost savings. Numerical simulations, which model various parts of the unsteady dynamics to reduce the computational expense of the simulation, must adequately capture the unsteady flow dynamics in the excited jet for the results are to be used. Four CFD methods are considered for use in an excited jet problem, including two turbulence models with an Unsteady Reynolds Averaged Navier-Stokes (URANS) solver, one Large Eddy Simulation (LES) solver, and one URANS/LES hybrid method. Each method is used to simulate a simplified excited jet and the results are evaluated based on the flow data, computation time, and numerical stability. The knowledge gained about the effect of turbulence modeling and CFD methods from these basic simulations will guide and assist future three-dimensional (3-D) simulations that will be used to understand and optimize a realistic excited jet for a particular application.

\section{SUBJECT TERMS}

Aerodynamic noise

\begin{tabular}{|c|c|c|c|c|c|}
\hline \multicolumn{3}{|c|}{ 16. SECURITY CLASSIFICATION OF: } & \multirow{2}{*}{$\begin{array}{l}\text { 17. LIMITATION OF } \\
\text { ABSTRACT } \\
\text { UU }\end{array}$} & \multirow{2}{*}{$\begin{array}{l}\text { 18. NUMBER } \\
\text { OF } \\
\text { PAGES } \\
20\end{array}$} & \multirow{2}{*}{$\begin{array}{l}\text { 19a. NAME OF RESPONSIBLE PERSON } \\
\text { STI Help Desk (email:help@sti.nasa.gov) } \\
\text { 19b. TELEPHONE NUMBER (include area code) } \\
\text { 443-757-5802 }\end{array}$} \\
\hline $\begin{array}{l}\text { a. REPORT } \\
\text { U }\end{array}$ & $\begin{array}{l}\text { b. ABSTRACT } \\
\mathrm{U}\end{array}$ & $\begin{array}{l}\text { c. THIS } \\
\text { PAGE } \\
\text { U }\end{array}$ & & & \\
\hline
\end{tabular}



